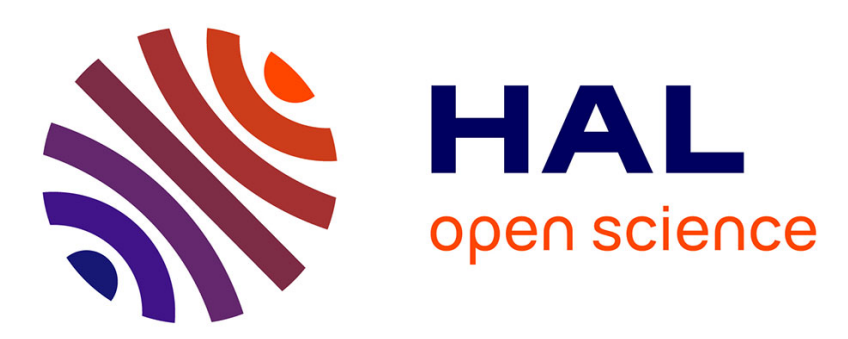

\title{
Quantitative Description of the Evolution in the Geometry of Grains in a Pure $\alpha-\mathrm{Fe}$
}

\author{
K. Kurzydlowski, M. Janicki
}

\section{To cite this version:}

K. Kurzydlowski, M. Janicki. Quantitative Description of the Evolution in the Geometry of Grains in a Pure $\alpha$-Fe. Journal de Physique IV Proceedings, 1995, 05 (C7), pp.C7-243-C7-246. 10.1051/jp4:1995727 . jpa-00254020

\section{HAL Id: jpa-00254020 https://hal.science/jpa-00254020}

Submitted on 1 Jan 1995

HAL is a multi-disciplinary open access archive for the deposit and dissemination of scientific research documents, whether they are published or not. The documents may come from teaching and research institutions in France or abroad, or from public or private research centers.
L'archive ouverte pluridisciplinaire HAL, est destinée au dépôt et à la diffusion de documents scientifiques de niveau recherche, publiés ou non, émanant des établissements d'enseignement et de recherche français ou étrangers, des laboratoires publics ou privés. 


\title{
Quantitative Description of the Evolution in the Geometry of Grains in a Pure $\alpha-F e$
}

\author{
K.J. Kurzydlowski and M. Janicki \\ Department of Materials Science and Engineering, Politechnika Warszawska (Warsaw University of \\ Technology), 02-524 Warszawa, Narbutta 85, Poland
}

\begin{abstract}
Grains in polycystals differ in their size and shape. The geometry of grains in a given polycrystal is described by the distribution functions of grain size and shape. These finctions can be experimentally studied using the methods of quantitative stereology and image analysis. The geometry of grains is related to the physical properties of the grain boundaries and vice versa. The distribution finction of the geometrical features of grains can help in the assessment of the physical propeties of the grain boundaries. Distribution functions of grains size and shape were investigated in an UHP iron produced at EMSE and in a commexially availale Armco iron. Populations of grains in the specimens studied were charaderized in terms of mean grain volume, $E(V)$, grain section area, $E(A)$ and the grain size diversity ratio. The data obtained in the study provide a quantitative description of the evolution in the geometry of grains during recrystallization and grain growth It was found that there are systematic differences in the geometrical features of grains in UHP iron and Armco iron. The possible contribution of these diffences to the disparity in the properties of the UHP materials is discussed.
\end{abstract}

\section{INTRODUCTION}

Grains in polycrystals differ in their size and shape. The geometry of grains in a given polycrystal is described by the distribution functions of grain size (for example grain volume) and the distribution functions of shape factors (for example the ratio of the maximum chord length to the equivalent diameter). The size and shape distribution functions can be experimentally studied using the methods of quantitative stereology and image analy sis [1]. It has been shown recently that these distribution functions reflect changes taking place in the material microstructures and that they influence the properties of the materials $[2,3]$.

The geometry of grains is related to the phy sical properties of the grain boundaries and vice versa. As a result, the distribution function of the geometrical features of grains can also help in the assessment of the phy sical properties of the grain boundaries. In the present study the distribution functions of size and shape of grains were investigated in an UHP iron produced at EMSE and, for comparison, in a commercially available Armco iron. The specimens were studied as a function of annealing temperature, time and amount of cold-working Populations of grains in the specimens studied were characterized in terms of mean grain size, (mean grain volume, $\mathrm{E}(\mathrm{V})$, or grain section area, $\mathrm{E}(\mathrm{A})$ ) and the grain size diversity ratio (defined as the ratio of the mean value to the standard deviation of a grain size parameter). The data obtained in the study provide a quantitative description of the evolution in the geometry of grains during recry stallization and grain growth. It was found that there are systematic differences in the geometrical features of grains in UHP Fe and the Armoo iron. Possible contribution of these differences to the disparity in the properties of UHP Fe is discussed.

\section{MATERIALS AND EXPERIMENTAL DETAIIS}

The studies were carried out on an UHP $\alpha$-Fe produced by a group at EMSE and for comparison on a commercially available Armo iron. The UHP material was delivered in the form of rods which were extruded 
were extruded and subsequently annealed at $500^{\circ} \mathrm{C}$ for annealing times in the range $0.25-8$ hours. Observations were performed on longitudinal and transverse cross-sections. Images of microstructures were digitalized and processed using an image analyzer. Measurements of nuclei/grain geometry were carried out using specially developed software. The following parameters of the individual nucleus and grain sections were measured:

A - grain/nucleus section area;

$\mathrm{d}_{2}$ - 2-D equivalent circle diameter of the nucleus/grain;

$\mathrm{d}_{\text {max }}$ - maximum section dimension;

These parameters were measured for individual nuclei/grains in order to obtain the experimental distribution functions of the listed parameters. The distribution functions were also described in terms of:

$\mathrm{E}(\mathrm{X})$ - mean value of $\mathrm{X}$;

$\mathrm{SD}(\mathrm{X})$ - standard deviation of $\mathrm{X}$;

$\mathrm{CV}(\mathrm{X})$ - coefficient of variation of $\mathrm{X},(\mathrm{CV}(\mathrm{X})=\mathrm{SD}(\mathrm{X}) / \mathrm{E}(\mathrm{X}))$.

$A$ and $d_{2}$, which define the size of the grain/nucleus sections can be used, under some assumptions, to infer the volume distribution of nuclei/grains [1]. The parameter $d_{\max }$ can be used to describe the shape of nuclei/grains [2] in terms of the shape factor defined as the ratio $d_{\max } / d_{2}$. This ratio, which equals 1 for a circle, describes the elongation of nucleus/grain sections. The other 3-dimensional characteristics measured in the present study included the volume fraction of the recrystallized material, $\mathrm{V}_{\mathrm{v}}$. This parameter was estimated using the standard stereological relationship:

$$
V_{V}=A_{A}
$$

where $A_{A}$ is the recrystallized area fraction (measured on sections of the material).

\section{RESULTS}

Figure 1 shows the plot of the un-recrystallized volume fraction, $\left(1-\mathrm{V}_{\mathrm{v}}\right)$, against the annealing time, $t$, on a double logarithmic scale. It may be noted that the experimental points do not fall on a straight line as predicted by basic theoretical models [3-5]. Figure 2 presents the estimated values of the number of nuclei/grains per unit volume, $\mathrm{N}_{\mathrm{v}}$, (for the details see [1]) again as a function of the annealing time, $t$. It can be observed that the density of the nuclei/grains decreases significantly during recrystallization.

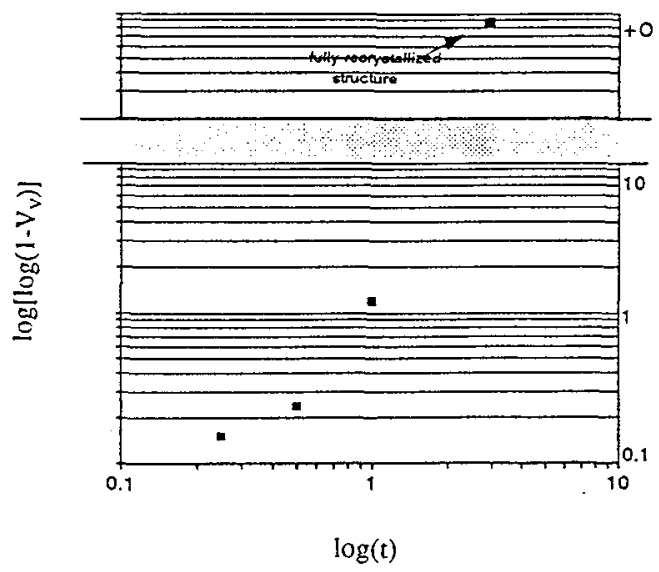

Figure 1 Plot of $\log \left(1-\mathrm{V}_{\mathrm{v}}\right)$ against Int. The two stages of recrystallization and grain growth are indicated on the scale of the annealing time.

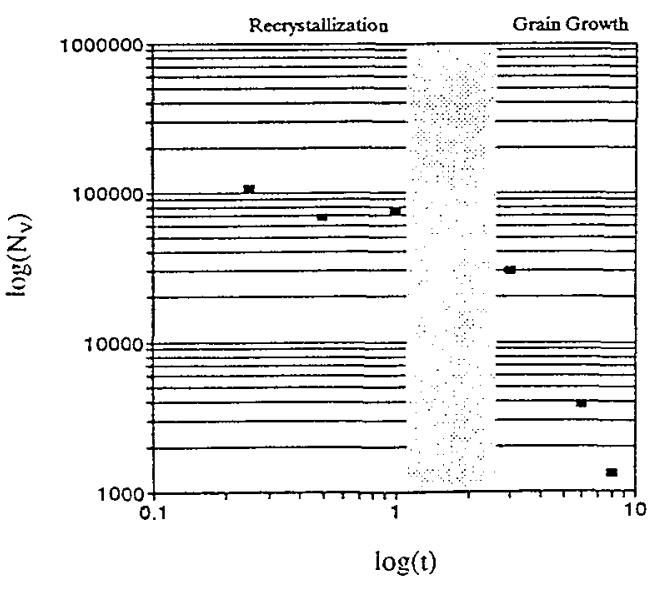

Figure 2 Plot of the number nuclei/grain in unit volume, $\mathrm{N}_{\mathrm{V}}$, against the annealing time in double logarithmic coordinates. 


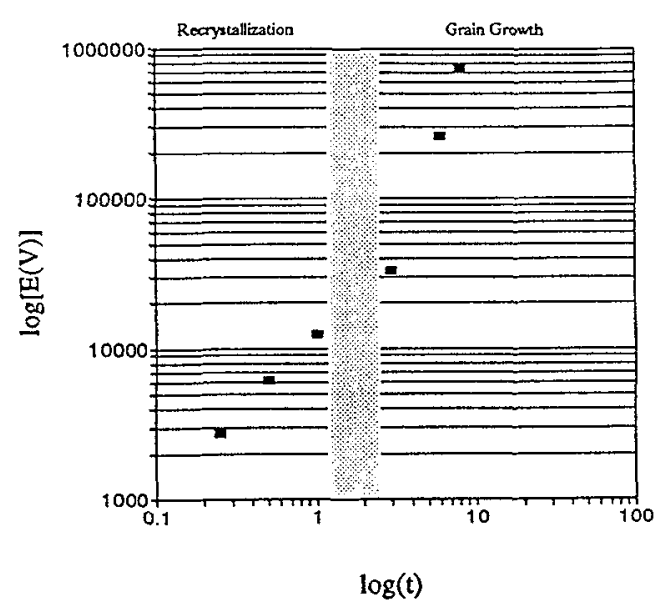

Figure 3 Dependence of the average volume of nuclei/grains on the annealing time in double logarithmic coordinates.

Figure 3, which illustrates changes in the mean volume of nuclei (and then the grains), $E(V)$, as a function of time, demonstrates that the process of recrystallization is accompanied by a systematic increase in the average size of nuclei/grains, E(V). The rate of growth of the average volume of nuclei/grains during recry stallization $\left(\mathrm{V}_{\mathrm{V}}<100 \%\right)$ is slower than the rate observed for the grain growth stage $\left(V_{V}=100 \%\right)$. Figure 4 shows the variation in the mean values of the shape factor used in the present study. It may be noted that the initial stages of recry stallization are characterized by increasing values of the $\mathrm{d}_{\max } / \mathrm{d}_{2}$ ratio, indicating increasing elongation of the nuclei. This grain elongation in fully-recrystallized material sharply decreases during the early stages of grain growth and remains almost constant for longer annealing times.

It has recently been shown that the properties of polycrystalline materials depend on both the mean grain size and the degree of grain size diversity [6]. In the present work the diversity in the size of grains was measured using the coefficient of variation of grain sections, CV(A). Figure 5 shows that the plot of $\mathrm{CV}(\mathrm{A})$ against the average grain size, $\mathrm{E}(\mathrm{A})$. It can be noted that the grain growth stage in the material stuctied is characterized by variations in the degree of the grain size diversity.

Similar measurements were carried out on a commercially available Armo iron. The results of these measurements are summarized in Table 1. It

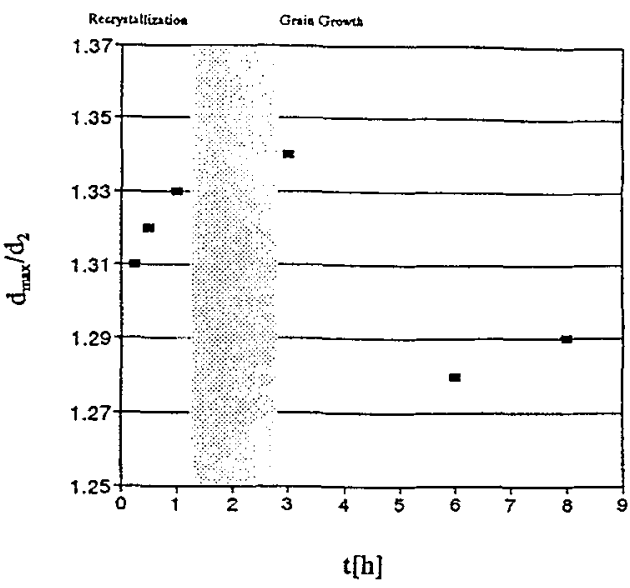

Figure 4 Variation in the values of the average value of the shape factor $d_{\max } / d_{2}$.

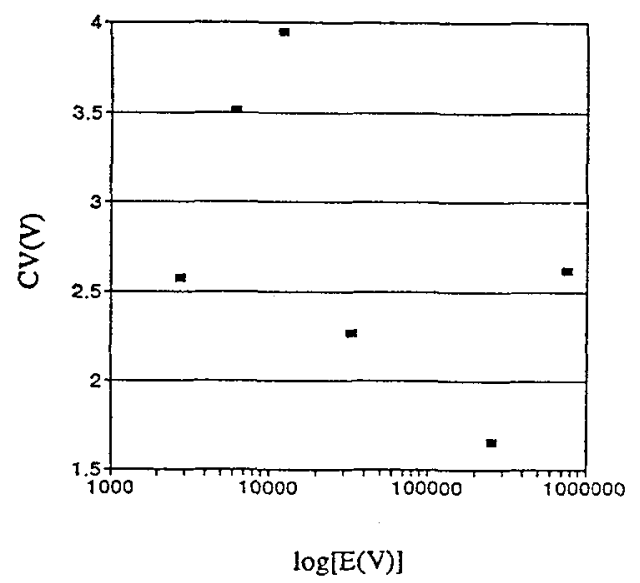

Figure 5 Plot of the coefficient of variation in the area of grain sectins, $C V(A)$, against the average grains size, $E(A)$.

\begin{tabular}{|c|c|}
\hline Material & CV(A) \\
\hline Armo & $0.9,1.4$ \\
\hline UHP & $1.2,1.8$ \\
\hline
\end{tabular}

Table I: Range of values of grain section area, coefficient of variation, $\mathrm{CV}(\mathrm{A})$, measured in an Armo and a UHP iron may be noted that an UHP Fe- $\alpha$ is characterized by a tendency to a higher diversity in the size of grains as indicated by the range of measured values of $\mathrm{CV}(\mathrm{A})$, i.e. the coefficient of variation of grain section area 


\section{DISCUSSION AND CONCLUSIONS}

The results obtained in the present study show that the recrystallization process is characterized by a decreasing density $\mathrm{N}_{\mathrm{v}}$ of nuclei/grains as a function of annealing time, $t$.

The observed dependence of $N_{v}$ on the annealing time, $t$, can be explained in terms of the superposition of nucleation of defect-free nuclei and their growth, which is accompanied by nucleus/grain annihilation.

The results of geometrical feature measurements of individual nuclei/grains show that the so called recrystallization analyzed on the mesoscopic scale does not meet the criterion of a steady state process. In fact it is characterized by alterations in the nucleus/grain size distribution function and considerable complexity in shape transformation of the individual nuclei/grains. The nuclei/grains initially become significantly elongated and their elongation increases during the recrystallization stage.

The results of the present studies proved that there is a significant difference in the degree of grain size uniformity in an UHP and Armco iron. The UHP iron generally shows a higher spread in the size of individual grains. This may be an indication of a tendency for abnormal grain growth in pure iron. On the other hand, both the size of grains and the degree of grain size uniformity influence the mechanical properties of polycrystalline materials. Based on the model described in [6], it may be suggested that these differences, in addition to the variation in the properties of the grain boundaries [8], may contribute to the distinctive properties of UHP $\alpha$-Fe.

\section{Acknowledgements}

One of the materials used in this study was manufactured at the Ecole Nationale Superieure Des Mines, 42023 Saint Etienne Cedex 2, FRANCE in the group directed by Prof. J. Le Coze.

\section{References}

[1] Bucki J.J. and Kurzydlowski K.J., Mater.Character., 29 (1992) 365-374.

[2] Kurzydlowski K.J., McTaggart K.J. and Tangri K., Phil.Mag., A 61 (1990) 61-83.

[3] Avrami M., J.Chem.Phys., 9 (1941) 177-184.

[4] Beck P.A., Advances in Physics, 3 (1954) 245-244.

[5] Cahn J.W., Acta Metall., 4 (1956) 449-459.

[6] Kurzydlowski K.J.and Bucki J.J., Acta Metall.Mater., 41 (1993) 3141-3146.

[7] Kurzydlowski K.J., Ralph B., Chojnacka A. and Bucki J.J., submitted to Acta Metall.Mater..

[8] Tacikowski M., Kobylanski A. and Grabski M.W., Colloque de Physique., 51 (1990) 653-658. 